\title{
Knowledge and Self-Care Practices among Psoriatic Patients in Benha City
}

\section{Elham Nabawy Mohamed ${ }^{1}$, Ebtisam Mohamed Abd Al-Aal ${ }^{2}$ and Mona Abdallah Abdel-Mordy ${ }^{3}$}

(1) B.Sc. Nursing (2) Professor of Community Health Nursing, Faculty of Nursing, Benha University.

(3) Lecturer of Community Health Nursing, Faculty of Nursing, Benha University.

\begin{abstract}
Background: Psoriasis is a common, chronic, non-communicable skin disease, with no clear cause or cure. The negative impact of this condition on people's lives can be immense. Psoriasis affects people of all ages, and in all countries. The reported prevalence of psoriasis in countries ranges between $0.09 \%$ and $11.43 \%$, making psoriasis a serious global problem with at least 100 million individuals affected worldwide. Psoriasis has an unpredictable course of symptoms, a number of external triggers and significant comorbidities, including arthritis, cardiovascular diseases, metabolic syndrome, inflammatory bowel disease and depression. The study aimed to assess knowledge and self-care practices among psoriatic patients. Research design: A descriptive research design was utilized to conduct this study. Setting: The study was conducted at Dermatology Hospital out-patient clinics and Dermatology Out-Patient Clinics of Benha University Hospital in Benha City. Sample: A convenient sample was selected from the above mentioned setting; it included 30 psoriatic patients. Tools: Two main tools. Tool I: A structured interviewing questionnaire Part I: A) Socio-demographic characteristic of the psoriatic patients, B) Past medical history of the psoriatic patient, c) Current medical history. Part II: Psoriasis Knowledge Questionnaire (PKQ). Tool II: The patients' self-care practices toward psoriasis. Results: $40 \%$ of studied patients aged more than 50 years old, 73,3\% of studied patients were males, $56.7 \%$ of psoriatic patients had poor total knowledge, While $23.3 \%$ of them had a good total knowledge score and $73.3 \%$ of studied patients had total unsatisfactory self-care practices score toward psoriasis. Conclusion: there was a positive correlation between the studied patients' total knowledge score and their total self-care practices score regarding psoriasis. Recommendation: Health educational program about psoriasis should be developed and implemented at outpatient clinics to improve patients' knowledge and self-care practices regarding psoriasis.
\end{abstract}

Keywords: Psoriasis, Patient, Knowledge and Practices.

\section{Introduction}

Psoriasis is a chronic recurrent immunemediated inflammatory skin disease with fluctuating disease severity. There is no difference between men and women in relation to the number of people affected and the disease may debut in all ages. Factors such as stressful life events and psychological distress appear to have significant effects on the onset or exacerbation of the disease (Ljosaa et al., 2017).

Psoriasis represents a significance public health challenge, affecting approximately 125 million people globally. Prevalence estimates within adult populations range from $0.91 \%$ in the United States of America (USA) to $8.5 \%$ in Norway (International Federation of Psoriasis Association (IFPA), 2018) 
The clinical features of typical patterns of psoriasis are Chronic plaque psoriasis is the most common type of psoriasis in children and adults, accounting for $55-90 \%$ of cases. The scalp, extensor elbows, knees and gluteal cleft are the most frequently involved sites. Plaques are erythematous with defined margins and often have a silvery scale. Scale is less evident after bathing or after the application of a moisturizer. The plaques are frequently pruritic. Inverse psoriasis affects one-quarter of people living with psoriasis. Signs of inverse psoriasis include inflamed deep-red skin that is smooth and not scaly. Inverse psoriasis affects skin folds in the body such as underarms, under breasts, in the genital area and buttocks. It can cause severe itching and pain and can be worsened by sweat and rubbing in these areas (The National Psoriasis Foundation (NPF), 2020).

Psoriasis patients often have a lower quality of life than the general population and an increased risk of concurrent disorders. Many patients suffer from extensive psychological difficulties such as anxiety, depression and pathological worry. Patients appear to lack knowledge about the disease, are often dissatisfied with their care and exhibit low adherence to medical treatments. In recent years, the relationships between disease activity and lifestyle parameters such as smoking, stress, Body Mass Index (BMI) and physical activity have been identified as areas where psoriasis patients can influence their illness in a positive or negative direction. Thus, the need for patient education and selfmanagement interventions appear to be particularly important for patients with psoriasis (Gelfand and Abuabara, 2019).

Community Health Nurses play a critical role in patient education and in the prevention and management of disease. The main focus for $\mathrm{CHN}$ is providing continuity of care for the patient by using the nursing process and the collaboration with the patient to meet their needs. So patients suffering from psoriasis should know how to care for selves to manage the symptoms (American Public Health Association (APHA), 2017).

\section{Significance of the study:}

Psoriasis is one of the most common skin diseases with a chronic and recurrent course. The disease requires systematic treatment and appropriate care. In Egypt psoriasis affect 2 million of the Egyptian citizen (Smeltzer \& Bare, 2016), so this study will be done to assess knowledge and self-care practices among psoriatic patients.

\section{Aim of the study}

This study aimed to assess knowledge and self-care practices among psoriatic patients in Benha city.

\section{Research questions:}

1. What is the psoriasis patients' knowledge about psoriasis?

2. What is the psoriasis patients' reported self-care practices toward psoriasis?

3. What is the relation between the psoriasis patient's knowledge and their reported self-care practices?

\section{Subject and Method}

Research design: A descriptive research design (describing distribution of disease and health related characteristics of the population) was utilized in this study.

\section{Setting:}

The study was conducted at Dermatology Hospital out-patient clinics and Dermatology Out-Patient Clinics of Benha University Hospital in Benha City.

\section{Sampling:}

A convenient sample was selected from the above mentioned setting. The total 
number of patients were 30 patient (12 psoriatic patients) from dermatology hospital, (18 psoriatic patients) from dermatology OutPatient Clinics Benha University Hospital In Benha City. Under the following criteria: Age from 20-60 years, alert, able to communicate, confirmed diagnosis with psoriasis and have no other dermatological disease.

Tools of data collection:

Two main tools were used for data collection.

\section{Tool I: A structured interviewing questionnaire: \\ This tool was designed by the investigator after reviewing related literature. It was designed in an Arabic language in the form of close and open ended questions. This questionnaire was consisted of two parts:}

\section{Part I:}

\section{(A) Socio-demographic characteristic of} the psoriatic patients as: Age, sex, marital status, educational level, occupation, place of residence and family monthly income.

(B) Past medical history of the psoriatic patient as type of psoriasis, beginning to complain of psoriasis, positivity family history of psoriasis, complaining from any other health problems and the main problem.

(C) Current medical history as (the current complain, any psychological problems, the impact of psoriasis on sexual relations, the current treatment).

Part II: Psoriasis Knowledge Questionnaire (PKQ) was adopted from Wahl et al., (2015). It was utilized to measure the psoriatic patient's knowledge about the disease: It contained 49 questions which included facts about the disease, psoriasis triggers, disease process and disease comorbidity and treatment.

\section{Scoring system:}

The psoriatic patients' knowledge scored as 1 point for correct answer and zero score for incorrect and don't know answer.

Total scores of knowledge $=49$ point .

The total knowledge scores was considered good if the score of the total knowledge is > $75 \%$ equal (> 37 point), while considered average if it is equal $50-75 \%$ equal (25-37 point) and considered poor if it is less than $<50 \%$ equal ( $<14$ point).

\section{Tool II: The patients' self-care practices toward psoriasis sheet:}

It consists of 4 items (skin care items, bathing items, diet items and prevention of psoriasis problems).

\section{Scoring system:}

Practice score for each response was given as follows: 1 score for done and zero for not done.

Total score for practices $=30$ point .

The total practices score was considered satisfactory if the score of the practices is $\geq$ $60 \%$ equal ( $\geq 18$ point) and considered unsatisfactory if it is $<60 \%$ equal ( $<18$ point).

\section{Content validity:}

The tool validity was done by five experts from Faculties Nursing Staff from the Community Health Nursing Specialties department.

\section{Tool reliability:}

The reliability of tools was applied by the investigator for testing the internal consistency of the tool. The tool reliability was measured using Cronbachs' Alpha 
perceived for patients knowledge was 0.89 and for practices was 0.61 .

\section{Ethical Consideration:}

Oral consent was obtained from each psoriatic patient before conducting the interview and the psoriatic patients were informed about the purpose and benefits of the study at the beginning of interview and informed that participation were voluntary and has the right to withdraw from the study at any time. Patients were also reassured that all gathered information would be treated confidentiality and used only for the aim of the study. No names were required on the forms to ensure anonymity and confidentiality.

\section{Pilot study:}

The pilot study was carried out on $10 \%$ (3 patients) of the total sample of studied patients having psoriasis from the Outpatient Clinic in Benha University Hospital. The pilot study was made to access the total clarity, applicability and time needed to fill each sheet as well as to identify any possible obstacles that may hinder the data collection. No any modification done to this number of patients included in this study sample.

\section{Field Work:}

The actual field work was carried out over a period of six months from the beginning of July 2020 up to the end of December 2020, for data collection. The investigator interviewed psoriatic patients at hospital after introducing herself and took their consent to be recruited in the study after explaining the aim of the study and then distributed the questionnaire sheet after clear explanations of the way to fill out and in the presence of the investigator. The tools took about 30 minutes to be answered from each patient. During the interview, the investigator read each item/ question on data collection and explains its meaning to the patients. Then the patients were asked to write down their answers. Patients were allowed to ask any interpretation, elaboration or explanation. The investigator visited 2 hospitals three days weekly, from 9am to $2 \mathrm{pm}$ till covering whole sample of each hospital. Confidentiality for all collected information was strictly assured.

\section{Statistical analysis:}

The collected data was analyzed, tabulated and presented in figures by using the suitable statistical methods as number and percentage distribution by Statistical Package for Social Science (SPSS) version 21. Data were presented by using proper statistical tests that were used to determine whether there were significant differences or not and if there were positive correlation or not. Chisquare and $\mathrm{z}$ test was used to detect the relations between the variables. Also P-value was used to determine significance of results as follows: $>0.05$ is non- statistically significant difference, $<0.05$ is statistically significant difference and $<0.001$ is highly statistically significant difference.

\section{Results:}

Table (1): Shows socio-demographic characteristics of the studied patients, $40 \%$ psoriatic patients aged 50 years old and above, $73.3 \%$ of them were males and $70 \%$ of them were married. Regarding educational level, $30 \%$ of the studied patients had intermediate education and $36.7 \%$ of them employed. $63.3 \%$ of them lived in rural areas with enough family income.

Table (2): Reveals that $86.7 \%$ of the studied patients had plaque psoriasis, $36.7 \%$ of them began to complain of psoriasis from 4 years and above. $86.7 \%$ of the studied patients 
hadn't family history regarding psoriasis, 70\% of them didn't complain from any other health problems.

Table (3): Shows current medical history of the studied patients and reveals that; $86.7 \%$ of the studied patients complained from scaling as a current complain, $53.3 \%$ of them suffered from psychological problems as embarrassment, anxiety and psychological stress, depression and low self- esteem. 83.3\% of the studied patients didn't have negative impact of psoriasis on sexual relations, $100 \%$ of them received topical therapy and $100 \%$ of them complied with the current treatment.

Figure (1): Shows that, $56.7 \%$ of psoriatic patients had poor total knowledge score about psoriasis, while $23.3 \%$ of them had good total knowledge score about psoriasis and $20 \%$ of them had average total knowledge score about psoriasis.
Figure (2): Illustrates that, $73.3 \%$ of the studied patients had total self-care practices unsatisfactory score toward psoriasis and $26.7 \%$ of them had total satisfactory self-care practices score toward psoriasis.

Table (4): Shows that, there were statistically significant correlation between total knowledge about disease comorbidity and treatment and total bathing practices while there was highly statistically significant correlation with total prevention of psoriasis problems practices. There was no statistically significant correlation between other items of knowledge and practices.

Table (5): Illustrated that; there was a positive correlation between the studied patients' total knowledge score and their total self-care practices score toward psoriasis. 
Table (1): Distribution of the studied patients regarding their socio-demographic characteristics $(n=30)$.

\begin{tabular}{|l|c|c|}
\hline Demographic characteristics: & No & $\%$ \\
\hline Age/ years & 5 & \\
$20-$ & 9 & 16.7 \\
$30-$ & 4 & 30.0 \\
$40-$ & 12 & 43.3 \\
$50+$ & & 40.0 \\
\hline Sex & 22 & 73.3 \\
Male & 8 & 26.7 \\
Female & & \\
\hline Marital status & 9 & 30.0 \\
Single & 21 & 70.0 \\
Married & & \\
\hline Educational level & 8 & 26.7 \\
Basic education & 9 & 30.0 \\
Intermediate education & 7 & 23.3 \\
Institutional education & 6 & 20.0 \\
\hline University education & & \\
\hline Occupation & 5 & 16.7 \\
Worker & 7 & 23.3 \\
Retired & 11 & 36.7 \\
Employee & 7 & 23.3 \\
Not working & 19 & 36.7 \\
\hline Place of residence & 93.3 \\
\hline Urban & & \\
Rural & & 30.0 \\
\hline Family monthly income & & 30.0 \\
Enough & & \\
Not enough & & \\
\hline
\end{tabular}


Table (2): Distribution of the studied patients regarding to their past medical history $(n=30)$.

\begin{tabular}{|l|c|c|}
\hline Past medical history & No & \% \\
\hline Type of psoriasis. & 26 & 86.7 \\
Plaque psoriasis & 6 & 20.0 \\
Erythrodermic psoriasis & & \\
\hline Beginning to complain of psoriasis & 3 & 10.0 \\
<6 months & 7 & 23.3 \\
6- months & 6 & 20.0 \\
9- months & 3 & 10.0 \\
1- years & 11 & 36.7 \\
4 + years & 4 & 13.3 \\
\hline Family history of psoriasis & 26 & 86.7 \\
Yes & & \\
No & 9 & 30.0 \\
\hline Complaining from any other health problems & 21 & 70.0 \\
Yes & & \\
No & 7 & 23.3 \\
\hline If yes, please state the main reason (N=9) & 2 & \\
Cardiac disease & 1 & \\
Endocrine disease such as diabetes & 3 & 10.0 \\
\hline Renal disease & & \\
Arthritis disease & & \\
\hline
\end{tabular}

** Answers were not mutually exclusive.

Table (3): Distribution of the studied patients regarding to their current medical history $(n=30)$

\begin{tabular}{|l|c|c|}
\hline Current medical history & No & \% \\
\hline Current complain & 26 & 86.7 \\
Scaling & 23 & 76.7 \\
Itching & 13 & 43.3 \\
Redness & 4 & 13.3 \\
Burning pain & 4 & 13.3 \\
Bleeding & 1 & 3.3 \\
Joints pain & 4 & 13.3 \\
\hline Fatigue & & \\
\hline Suffering from any psychological problems due to psoriasis & 16 & 53.3 \\
Yes & 14 & 46.7 \\
\hline No & & \\
\hline Psychological problems (N=16) & 15 & 93.8 \\
Embarrassment & 9 & 56.3 \\
Anxiety and psychological stress & 5 & 31.3 \\
Depression & 1 & 6.3 \\
\hline Low self- esteem & 5 & 16.7 \\
\hline Negative impact of psoriasis on sexual relation & 25 & 83.3 \\
Yes & & \\
No & 30 & 100.0 \\
\hline The current treatments (N=30) & 4 & 13.3 \\
Topical therapy & 10 & 33.3 \\
\hline Photo therapy & 30 & 100.0 \\
\hline Systematic therapy & & \\
\hline Compliance with current treatment (N=30) & & \\
Yes & & \\
\hline
\end{tabular}

** Answers were not mutually exclusive. 


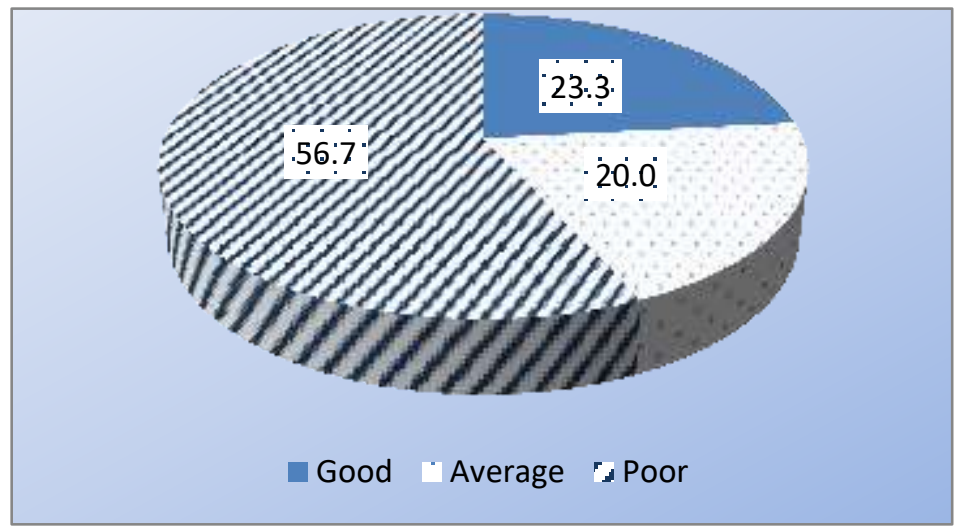

Figure (1): Percentage distribution of the studied patients regarding their total knowledge score about psoriasis $(n=30)$.

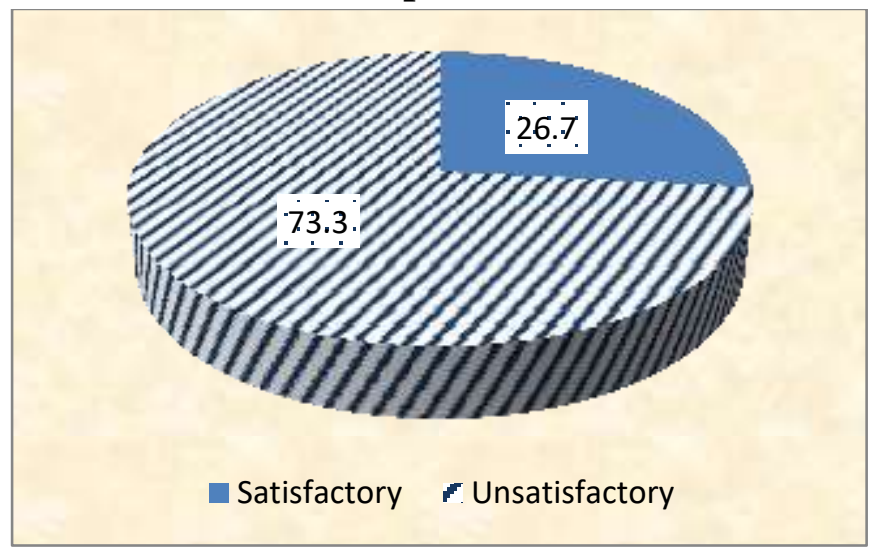

Figure (2): Percentage distribution of the studied patients regarding their total self-care practices score toward psoriasis $(n=30)$.

Table (4): Correlation between total knowledge items and total self-care practices items regarding

\begin{tabular}{|c|c|c|c|c|c|}
\hline \multirow{2}{*}{\multicolumn{2}{|c|}{ Total knowledge items }} & \multicolumn{4}{|c|}{ Total practices items } \\
\hline & & \multirow{2}{*}{$\begin{array}{c}\begin{array}{c}\text { Total skin care } \\
\text { practices }\end{array} \\
.149\end{array}$} & \multirow{2}{*}{$\begin{array}{c}\begin{array}{c}\text { Total } \\
\text { bathing } \\
\text { practices }\end{array} \\
.244\end{array}$} & \multirow{2}{*}{$\begin{array}{c}\text { Total diet } \\
\text { Practices } \\
.163 \\
\end{array}$} & \multirow{2}{*}{ 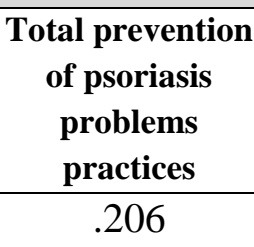 } \\
\hline Total knowledge about facts & $\mathrm{r}$ & & & & \\
\hline of disease. & p-value & .433 & .194 & .388 & .274 \\
\hline \multirow{2}{*}{$\begin{array}{c}\text { Total knowledge about } \\
\text { psoriasis triggers. }\end{array}$} & $\mathrm{r}$ & .048 & .030 & .172 & .101 \\
\hline & p-value & .801 & .875 & .362 & .595 \\
\hline \multirow{2}{*}{$\begin{array}{l}\text { Total knowledge about } \\
\text { disease process. }\end{array}$} & $\mathrm{r}$ & .093 & .161 & .300 & .265 \\
\hline & p-value & .623 & .396 & .107 & .158 \\
\hline \multirow{2}{*}{$\begin{array}{c}\text { Total knowledge about } \\
\text { disease comorbidity and } \\
\text { treatment. }\end{array}$} & $\mathrm{r}$ & .057 & .522 & .280 & .556 \\
\hline & $\mathrm{p}$-value & .767 & .003 & .133 & .001 \\
\hline
\end{tabular}


Table (5): Correlation between total knowledge score of the studied patients and their total self-care practices score $(n=30)$

\begin{tabular}{|l|l|l|}
\hline \multirow{2}{*}{ Total practices score } & \multicolumn{2}{|c|}{ Total knowledge score } \\
\cline { 2 - 3 } & $\mathrm{r}$ & $\mathrm{p}$-value \\
\cline { 2 - 3 } & 0.118 & 0.536 \\
\hline
\end{tabular}

\section{Discussion:}

Psoriasis is an inflammatory skin disease that typically follows a relapsing and remitting course. The prevalence of psoriasis is estimated to be around $1.3-2.2 \%$ in the UK. Psoriasis can occur at any age, although is uncommon in children $(0.71 \%)$ and the majority of cases occur before 35 years. Plaque psoriasis is characterized by well-delineated red, scaly plaques that vary in extent from a few patches to generalized involvement. It is by far the most common form of the condition about $90 \%$ of people with psoriasis. Other types of psoriasis include guttate psoriasis, erythrodermic and pustular (localized or generalized) forms. Distinctive nail changes occur in around $50 \%$ of all those affected and are more common in people with psoriatic arthritis. Psoriasis is associated with joint disease in a significant proportion of patients reported in one study at 13.8\% (Parisi et al., 2019).

The finding of present study revealed that, more than one third of the studied subjects aged 50 years to more, this could be due to psoriasis is chronic disease and had decrease rate of disease progression. This finding is accordance with Maindal and Lomborg, (2016) who conducted study entitled: selfmanagement in daily life with psoriasis: an integrative review of patient needs for structured education and stated that the majority of her studied sample was at age between 40 and 52 years.
As regards to gender, the result of the present study showed that, more than two thirds of studied patients were males, This finding is in-agreement with Ferrándiz and Carrascosa, (2016) who conducted study entitled: Prevalence of psoriasis in Spain in the age of biologics and mentioned that prevalence was higher in men than in women. However this finding is not in accordance with the results of Wahl et al., (2017) who conducted study entitled: Psoriasis patients' knowledge about the disease and treatments and found that around half of her studied group were women. And this finding disagrees with the result of Romiti et al., (2017) who conducted study entitled: Prevalence of psoriasis in Brazil - a geographical survey and found that psoriasis equally affects both genders.

Regarding the types of psoriasis, the results of this study revealed that, plaque-type psoriasis was the major clinical type had in studied patients and the lower present had psoriatic erythroderma, this finding is compatible with Takahashi et al., (2018) who conducted study entitled: Analysis of psoriasis patients registered with the Japanese Society for Psoriasis and stated that the majority of patients had plaque psoriasis.

Regarding the present history of the studied patients, this study showed that the chief complains of the studied patients were scaling of the skin, itching, erythema, fatigue, 
burning and bleeding, this is supported by WHO, finding (2016) which conducted study entitled: Global report on psoriasis and found that symptoms of psoriasis can include scaling of the skin in $92 \%$, itching in $72 \%$, erythema in $69 \%$, fatigue in $27 \%$, swelling in $23 \%$, burning in $20 \%$, bleeding in $20 \%$ of individuals.

The duration of psoriasis in studied patients were more than one third of studied patients had duration of psoriasis four years or more, this finding is in-agreement with Preethi et al., (2018) who conducted study entitled: Correlation between disease severity, family income, and quality of Life in psoriasis: A study from South India and found that almost a quarter $(23.5 \%)$ of the patients had been suffering from the disease for more than 5 years.

Regarding to the percentage distribution of the studied patients regarding their total knowledge score about psoriasis, the findings of the present study showed that, more than half of the studied patients $(56.7 \%)$ had poor total knowledge score. This may be due to poor health education about the disease, lack of information about psoriasis and might be due to low level of education to the majority $(80 \%)$ of the studied patients.

About three quarters $(73.3 \%)$ of the studied patients had unsatisfactory total reported self-care practices score toward psoriasis. This may be due to lake of knowledge to most of the studied patients about psoriasis that influence into their practices toward disease.

The findings of the present study showed that there were highly statistically significant correlation between total knowledge about disease comorbidity and treatment and total prevention of psoriasis problems practices. This may be due to the patients had knowledge about disease comorbidity and treatment, high level satisfaction of them about total prevention of psoriasis problems practices.

Regarding to correlation between total knowledge score of the studied patients and their total reported practices score, the findings of the present study showed that there was a positive correlation between the studied patients' total knowledge score and their total reported practices score. This agrees with Wahl et al., (2019), who studied: Clinical Characteristics Associated with Illness Perception in Psoriasis in Gran Canaria and they found that; there was strongly relation between the participants' knowledge and their total reported practices.

\section{Conclusion:}

Two fifths of the studied patients aged 50 years old and above, about three quarters of them were males and less than one third of them had intermediate education. The majority of the studied patients had plaque psoriasis, the majority of the studied patients complained from scaling as a current complain, all of them received topical therapy and all of them applied topical therapy. More than half of psoriatic patients had poor knowledge about psoriasis, while approximately three quarters of the studied patients had unsatisfactory reported self-care practices toward psoriasis. There was a positive correlation between the studied patients' total knowledge level and their total self-care reported practices level.

\section{Recommendations:}

1. Health educational program about psoriasis should be developed and implemented at outpatient clinics to improve patients' knowledge and self-care practices regarding psoriasis.

2. A colored illustrated booklet should be available and distributed to each psoriatic 
patient about self-care practices as (guidelines of hygienic care, skin care, managing psoriasis triggers and psoriasis diet).

\section{References:}

American Public Health Association (APHA), (2017). The Definition and Practice of Public Health Nursing. Available at: https://degree.lamar.edu/articles/nursing/what -is-community-nursing.aspx accessed on 110-2020.

Dubertret, L., Mrowietz, U., Ranki, A., van, D., Kerkhof, P.C., Chimenti, S., Lotti, T. and Schäfer, G. (2018). EUROPSO Patient Survey Group. European Patient Perspectives on the Impact of Psoriasis: the EUROPSO Patient Membership Survey, Br J Dermatol; 155(4):729-36.

Ferreira, B.R., Pio-Abreu, J.L., Reis, J.P. and Figueiredo, A. (2017). Analysis of the Prevalence of Mental Disorders in Psoriasis: The Relevance of Psychiatric Assessment in Dermatology, Psychiatria Danubina; 29(4):401-406.

Gelfand, J.M. and Abuabara, K. (2019). Diet and weight loss as a treatment for psoriasis. Arch Dermatol;146:544-6.

International Federation of Psoriasis Association (IFPA), (2018). World Psoriasis Day 2018. Available at: https://ifpapso.com/our-actions/worldpsoriasis- accessed at: Dec. 2020.

Ljosaa, T.M., Mork, C., Stubhaug, A., Moum, T. and Wahl, A.K. (2017). Skin Pain and Skin Discomfort is Associated with Quality of Life in Patients with Psoriasis, J Eur Acad Dermatol Venereol;(26):29-35.

Maindal T.H and Lomborg K., (2016). SelfManagement in Daily Life with Psoriasis: An Integrative Review of Patient Needs for Structured Education.Received10 Jul 2016, Revised26 Sep 2016, Accepted 10 Oct 2016 and Published06 Dec 2016.
Preethi, B., Nayak, B., Girisha, H. and Tonita, M. (2018). Correlation between Disease Severity, Family Income, and Quality of Life in Psoriasis: A study from South India. Indian Dermatol Online J. 2018 MayJun; 9(3): 165-169.

Parisi, R., Griffiths, C. and Ashcroft, D. (2019). Systematic review of the incidence and prevalence of psoriasis, British Journal of Dermatology; (165): e5.

Romiti, R., Amone, M., Menter, A. and Miot, H.A. (2017). Prevalence of psoriasis in Brazil - a geographical survey. Int J Dermatol. 2017 Aug; 56(8):e167-e168.

Smeltzer, S. and Bare, B. (2016). Brunner and Suddarth's Textbook of Medical Surgical Nursing.12th Ed.2016: 2160-1.

Takahashi, H., Nakamura, K., Fumio, K., Hidemi, N. and Hajime, I. (2018). Analysis of Psoriasis Patients Registered with the Japanese Society for Psoriasis, Journal of Dermatology (J Dermatol), Vol: 38, Issue: 12, P: 1125-1129.

The National Psoriasis Foundation (NPF), (2020). Types of Psoriasis. Available at: https://www.psoriasis.org/typesofpsoriasis/

Accessed on: 5-12-2020.

Wahl AK, Moum T, Robinson HS, Langeland E, Larsen MH and Krogstad AL (2017). Psoriasis Patients' Knowledge about the Disease and Treatments, Dermatol Res Pract; (2016):921737 .

Wahl, A., Moum, T., Robinson, H., Langeland, E. and Larsen, M. (2015). Psoriasis Patients' Knowledge about the Disease and Treatments, Hindawi Publishing Corporation Dermatology Research and Practice.

World Health Organization (WHO), (2016). Global Report on Psoriasis. WHO, https://apps.who.int/iris/handle/10665/204417 accessed on 2/ 12/ 2021. 


\section{معلومات وممارسات الرعاية الذاتية بين مرضى الصدفية فى مدينة بنها إلهام نبوي محمه - إبتسام محمد عبدالعال - منى عبدالله عبدالمرضي}

يعتبر مرض الصدفية من الامر اض المزمنة، الغير معدية التى تسبب التهاب الجلد. والتى تحدث نتيجة

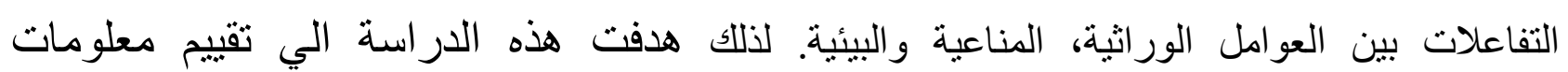
وممارسات الرعاية الذاتية بين مرضى الصدفية فى مدينة بنها. حيث أجريت هذه الدراسة بمستشفى الأمر اض الجلدية والعيادات الخارجية للأمر اض الجلدية بمستشفى جامعة بنها بمدينة

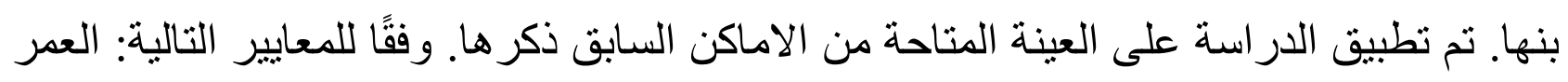

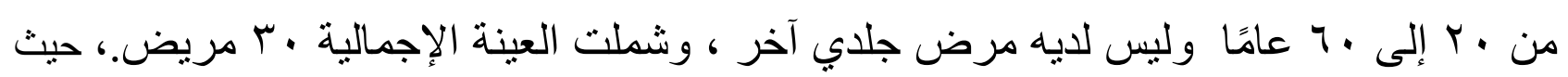
كثفت النتائج بوجود ارتباط إيجابي بين معلومات المرضى الكلية الخاضعين للاراسة ودرجة ممارساتهم للرعاية الذاتية. كما أوصت الدراسة بأهمية تطبيق برنامج التثقيف الصحي للمرضى فيما يتعلق بمعرفتهم

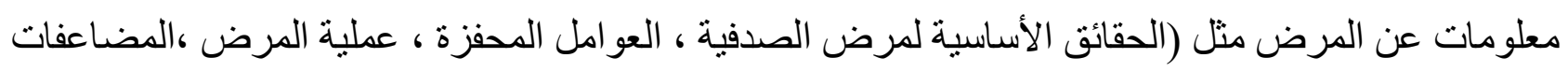
و العلاج).. معلمان. 